\title{
Management of appendiceal mass and abscess in children; early appendectomy or initial non-operative treatment? A systematic review and meta-analysis
}

\author{
Paul van Amstel ${ }^{1} \mathbb{0} \cdot$ Tania C. Sluckin ${ }^{1} \cdot$ Tim van Amstel ${ }^{1} \cdot$ Johanna H. van der Lee ${ }^{2,3} \cdot$ Ralph de Vries $^{4}$. \\ Joep P. M. Derikx ${ }^{1} \cdot$ Roel Bakx $^{1} \cdot$ L. W. Ernest van Heurn ${ }^{1} \cdot$ Ramon R. Gorter $^{1}$
}

Received: 15 May 2020 / Accepted: 10 July 2020 / Published online: 24 July 2020

(C) The Author(s) 2020

\begin{abstract}
Background Appendiceal mass and abscess and its treatment are associated with significant morbidity and high costs. Still, the optimal treatment strategy is the point of debate. Therefore, this systematic review and meta-analysis aimed to compare overall complications between initial non-operative treatment (NOT) and early appendectomy (EA) in children with appendiceal mass and/or abscess.

Methods Pubmed and Embase were searched. Only randomized controlled trials and prospective or historical cohort studies that compared NOT with EA in children with appendiceal mass or abscess in terms of complications were eligible for inclusion. Risk of bias was assessed. Primary outcome was the overall complication rate. Secondary, length of stay and readmission rate were investigated. A meta-analysis of overall complications associated with both treatment strategies was performed. Results 14 of 7083 screened studies were selected, including 1022 children in the NOT group and 333 in the EA group. Duration of follow-up ranged between four weeks and 12 years. Risk of bias was moderate in four and serious in 10 studies. NOT was associated with a lower overall complication rate (risk ratio (RR) 0.37 [95\% confidence interval (CI) $0.21-0.65]$ ). However, NOT led to increased length of stay (mean difference varied between 0.2 and 8.4 days) and higher readmission rate (RR 1.75 [95\% CI 0.79-3.89]), although not significantly. Interval appendectomy after NOT was performed as a routine procedure in all but one study. This study found a recurrence rate of $34 \%$ in a group of 38 patients during a follow-up period of $3.4 \pm 1.7$ years.

Conclusion NOT may reduce the overall complication rate compared to EA, but the evidence is very uncertain. As evidence is scarce, and of low level, and heterogeneity between studies is substantial, the results should be interpreted with caution. Large prospective studies are needed to determine the optimal treatment strategy for children with appendiceal mass and/ or abscess.
\end{abstract}

Keywords Appendicitis $\cdot$ Children $\cdot$ Appendiceal mass $\cdot$ Appendiceal abscess $\cdot$ Non-operative treatment $\cdot$ Appendectomy

\section{Background}

In the pediatric population, complex appendicitis is common, especially in children $<7$ years old [1]. Approximately $35 \%$ of children with acute appendicitis present with the

Electronic supplementary material The online version of this article (https://doi.org/10.1007/s00464-020-07822-y) contains supplementary material, which is available to authorized users.

Paul van Amstel

p.vanamstel@amsterdamumc.nl

Extended author information available on the last page of the article complex form. Although a uniform definition of complex appendicitis is lacking, in most studies it represents a spectrum ranging from gangrenous appendicitis to perforated appendicitis with generalized peritonitis. Generally, complex appendicitis can be divided into two main subgroups: without appendiceal mass and/or abscess (75\%) and with appendiceal mass and/or abscess (25\%) [1].

In general, complex appendicitis and its treatment are associated with significant morbidity (complications occurring in up to $30 \%$ of patients), prolonged length of hospital stay, and high costs [2]. Heterogeneity in the treatment of children with an appendiceal mass and/or abscess (e.g., initially non-operative treatment versus early appendectomy) 
still exists in daily practice. Some (pediatric) surgeons prefer initially non-operative treatment consisting of intravenous antibiotics (with or without percutaneous drainage), since this strategy is associated with less complications [3]. Others favor early appendectomy because a second trip to the hospital in order to perform an interval appendectomy can be avoided and, if the interval appendectomy is not performed as same day procedure, a shorter length of hospital stay is expected. This is one of the main reasons why early appendectomy is recommended by the Dutch guideline on the diagnosis and treatment of acute complex appendicitis as well [4]. This recommendation is merely based on expert opinion and in contrast to the limited and low-quality evidence.

In 2010 Simillis et al. published a meta-analysis that focused specifically on the treatment of appendiceal mass and abscess in both the adult and pediatric population. This meta-analysis could only include eight low-quality studies in the pediatric population and found that initial non-operative treatment was associated with a lower rate of overall complications (OR 0.21: 95\%CI 0.11-0.38), wound infections (OR 0.22: 95\%CI 0.07-0.66), and abscess formation (OR 0.11 : $95 \%$ CI $0.04-0.35$ ) compared to early appendectomy [3]. Since then, additional studies regarding the treatment of appendiceal mass and abscess in the pediatric population have been published that might provide novel insights [5, 6].

Therefore the aim of this systematic review and metaanalysis is to provide a complete overview of available literature regarding the treatment of the specific group of children presenting with appendiceal mass and abscess (identified according to predefined criteria) and to evaluate the effect of initial non-operative treatment (iv antibiotics with or without percutaneous drainage) (NOT) compared to early appendectomy (EA) on the rate of complications.

\section{Methods}

The protocol of this systematic review and meta-analysis was registered at PROSPERO: International prospective register of systematic reviews with identification number CRD42018083522. This systematic review and metaanalysis was reported according to the Preferred Reporting Items for Systematic reviews and Meta-analysis (PRISMA) guidelines [7]. Ethical approval and written informed consent were not required, as this study only analyzed previously published data.

\section{Type of studies}

All studies comparing EA with initial non-operative treatment for the management of appendiceal mass or abscess in children younger than 18 years were eligible for inclusion.
Randomized controlled trials, prospective cohort studies and retrospective cohort studies were included in the review, whereas case series, case reports, letters to the editor, and conference abstracts were excluded. Language was restricted to English, German, French, and Dutch. Only studies that reported on our primary outcome, complication rate associated with both treatment strategies, were eligible for inclusion.

\section{Type of participants}

Participants were children ( $<18$ years old) with complex appendicitis with the subtype of appendiceal mass and/or abscess. Only studies that defined their population at least with the terms 'appendiceal mass/phlegmon' or 'appendiceal abscess' were included. For further specification of these terms, definitions used in the original studies were followed.

\section{Types of interventions}

Intervention: Initial NOT strategy consisting of administration of intravenous antibiotics (with or without percutaneous drainage) with in-hospital monitoring and administration of pain medication followed or not followed by interval appendectomy. Duration and type of antibiotics were not defined.

Comparison: Operative treatment strategy, consisting of an immediate ( $<48 \mathrm{~h}$ after presentation) laparoscopic or open appendectomy with perioperative care according to local protocol. Studies comparing delayed appendectomy ( $>48 \mathrm{~h}$ after presentation) as primary treatment strategy with NOT were excluded.

\section{Search methods}

A comprehensive search was performed in the bibliographic databases PubMed and Embase.com in collaboration with our experienced medical librarian (RV). Databases were searched from inception up to November 7th 2019. The following terms were used (including synonyms and closely related words) as index terms or free text words: "Appendix", "Appendectomy", "Laparoscopy", "Children". A detailed search strategy is shown in Online Appendix 1. The reference lists of all included articles were cross-checked for identification of additionally relevant studies.

\section{Study selection and data extraction}

Two reviewers (PA, TS) selected eligible articles independently; these were initially screened on title and abstract according to the predefined inclusion and exclusion criteria. Following this initial selection full texts were screened. After final selection of the included articles, two independent reviewers (PA, TS) extracted data using a predefined 
data extraction form. Data extraction included the following variables, but this list is not exhaustive: general information (author, year, methodology, patient characteristics, definition of appendiceal mass and/or abscess, treatment strategies, follow-up), primary outcome (complication rate), and secondary outcomes (i.e., length of hospital stay, recurrent appendicitis, and readmission rates). Discrepancies in both study selection and data extraction were resolved by consensus, and in case of disagreement a third reviewer was consulted (RG). Authors were contacted by email in case of missing outcome data. Correspondence did not lead to additional data.

\section{Outcomes and definitions}

The primary outcome parameter was the overall complication rate in both treatment groups, defined as the proportion of patients experiencing at least one complication.

Complications of NOT included but were not limited to failure of NOT, i.e., patients not responding to the initial antibiotic treatment (with or without initial percutaneous drainage) and thus requiring additional interventions (e.g., additional drainage procedures, delayed appendectomy), and complications after interval appendectomy (as defined by the original authors).

Complications of operative treatment included but were not limited to extensive bowel resection and reoperations (as defined by the original authors).

Overall complications in both treatment groups included but were not limited to intra-abdominal abscess formation (IAA), superficial site infection (SSI) and ileus, as defined by the original authors.

If possible, complications were listed according to the Clavien-Dindo scale [8]. Grade 1: Any deviation from normal postoperative course without the need for farmacological treatment or a surgical/radiological intervention, Grade 2: Requiring farmacological treatment, Grade 3: Requiring surgical/radiological intervention, Grade 4: Life-threatening complication requiring ICU-admittance, Grade 5: Death of a patient.

Secondary outcomes included initial and total length of hospital stay (days) (total length of stay included interval appendectomy), readmission rate (defined as number of discharged patients that were admitted to the hospital again with complaints related to the previously experienced appendicitis), recurrent appendicitis (defined as number of patients who experienced symptomatic recurrence of disease with histopathologically proven recurrent appendicitis after completion of the initial course of antibiotics), number and type of imaging studies (ultrasound, Computed Tomography (CT), and Magnetic Resonance Imaging (MRI)), usage of pain medication (number of doses and type of pain medication (acetaminophen, non-steroidal anti-inflammatory drugs
(NSAIDs), and morphine)), unexpected findings during surgery or at histopathological examination, number of surgical and/or radiological interventions, and Quality of Life (as defined by the original authors).

\section{Risk of bias and quality of evidence assessment}

Two reviewers (PA, TA) applied the Cochrane Collaboration's Risk of Bias Tool 2.0 for randomized controlled trials and the Risk Of Bias In Non-randomised Studies of Interventions (ROBINS-I) tool depending on the study design $[9,10]$. Specifically bias due to confounding and bias in selection of participants were of importance. Bias due to confounding was considered low in randomized controlled trials, and moderate in prospective cohort studies and retrospective cohort studies that adjusted for baseline characteristics. Retrospective cohort studies that did not adjust for baseline characteristics were assessed as serious risk of bias. For all included studies risk of bias due to selection was assessed as low, moderate or serious according to the moment that patients were diagnosed with appendiceal mass or abscess:

- Low risk of selection bias: all patients included in the study were diagnosed with appendiceal mass or abscess (by physical examination or imaging) before the start of the intervention (i.e., non-operative treatment or early appendectomy).

- Moderate risk of selection bias: at least 50\% of patients, but not all were diagnosed before the start of the intervention. Meaning that less than $50 \%$ of patients were diagnosed with appendiceal mass or abscess during or after the intervention.

- Serious risk of selection bias: less than $50 \%$ of patients had a diagnosis of appendiceal mass or abscess before the start of the intervention. Thus more than $50 \%$ of patients were diagnosed with appendiceal mass or abscess during or after the intervention. Both risk of bias tools were applied on the outcome level (overall complication rate) independently by the two authors. Conflicts were resolved by discussion until consensus. In case of persistent disagreement a third author (RG) was consulted.

Evidence of the studies and their original conclusions were rated according to the Oxford Centre for EvidenceBased Medicine Levels of Evidence Table [11].

Certainty of the evidence and conclusions of this systematic review and meta-analysis was evaluated using the Grading of Recommendations Assessment, Development and Evaluation (GRADE) method. GRADEpro software was used to create a Summary of Findings table for all pooled outcome measures and sensitivity analyses of studies at moderate risk of bias. The five GRADE considerations (study limitations, consistency of effect, imprecision, 
indirectness, and publication bias) were used to grade the evidence and conclusions. All decisions to downgrade the quality of the evidence were justified using footnotes.

\section{Data analysis}

In case less than $50 \%$ of included studies reported on one of the outcome measures, meta-analyses were not performed. Furthermore, if statistical heterogeneity exceeded $70 \%$, it was decided not to show the pooled effect estimate. Review Manager version 5.3.5 was used for the performance of the meta-analyses. The Mantel-Haenszel method was used to compute risk ratios and their corresponding $95 \%$ CI for dichotomous outcomes and to calculate weighted mean differences with $95 \% \mathrm{CI}$ for continuous data. Means and variances were calculated according to the Cochrane Handbook for Systematic Reviews of Intervention [9]. Heterogeneity was assessed with the Higgins $I^{2}$ inconsistency test. When $I^{2}$ was more than $50 \%$, statistical heterogeneity was considered substantial. Meta-analyses were performed using a random-effects model. Publication bias was assessed with funnel plots.

Sensitivity analyses were performed to examine the treatment effects on the primary outcome (overall complications) excluding studies with serious risk of bias (i.e., perioperative selection of patients), studies published before 2000, and studies without a well described definition of appendiceal abscess or mass. For the secondary outcomes sensitivity analyses were limited to studies with low or moderate risk of bias, by excluding the studies with serious risk of bias, and to studies published after 2000. Studies were divided into those reporting on patients presenting with appendiceal mass, those focusing on appendiceal abscess, and those analyzing a combination of both. Subsequently, overall complications were analyzed for these subgroups of studies.

Additionally an analysis was performed wherein the primary outcome (overall complication rate) was divided in IAA, wound infection, and ileus.

\section{Results}

\section{Search}

The search yielded 9442 articles, of which 4438 were found in Pubmed and 5004 in Embase. After removal of duplicates, 7083 articles were screened for title and abstract and 220 studies were assessed for full text. 206 articles were excluded because of various reasons. Fourteen studies were included in the systematic review and meta-analysis $[5,6$, 12-23]. See Fig. 1 for a flowchart of the study selection.

\section{Included studies}

The general characteristics of the included studies are shown in Table 1. Designs of the studies were one pilot randomized controlled trial [6], two non-randomized prospective studies $[5,18]$, and 11 retrospective studies [12, 13, 15-23]. These 14 studies included 1355 children, of which 333 were included in the EA group with a median [range] of 19 patients [7-60] per study and 1022 in the NOT group with a median [range] of 32 patients [6-411] per study. The papers were published between 1969 and 2016. Follow-up ended for most studies after interval appendectomy with a range of four [22] -23 weeks [21] after initial NOT [6,12-19.] Two studies reported long-term follow-up of 3-12 years [5, 23].

\section{Quality of the studies}

The interrater reliability for overall judgment of risk of bias was good ( $86 \%$ agreement). In only $14 \%$ of cases a third author was consulted. The interrater reliability for judging the subdomains of the ROBINS-I and Risk of Bias tool 2.0 was substantial (76\% agreement). All studies were assessed as moderate to serious risk of bias on the primary outcome (overall complication rate) according to the ROBINS-I tool and some concerns were expressed according to the Risk of Bias tool 2.0 for the study by St Peter (Table 2) [5, 6, 12-23]. Bias due to confounding was serious in most cohort studies and moderate in only 4 of them $[5,13,18,21]$. These four studies adjusted for baseline characteristics and all participants were preoperatively selected for inclusion.

Risk of bias in selection of participants was low in eight $[5,12-14,18,19,21,22]$, moderate in two $[16,20]$ and serious in two studies [17, 23].

Evidence and conclusions of the original studies were rated as level $2 b$ in 3 studies $[5,6,18]$ and level 4 in 11 studies [12, 13, 15-23].

\section{Primary outcome: Overall complication rate}

A total of 1355 patients were included in the analysis, of which 1055 were treated initially non-operatively and 333 underwent EA. In the NOT group 125 of 1022 patients (12.2\%) experienced a complication. In the EA group a complication occurred in 85 of 333 patients (25.5\%). Most reported complication in the NOT group was failure of NOT ( $80 \%$ of patients with a complication). For the EA group IAA was the most common complication ( $48 \%$ of patients with a complication). Due to the lack of available data it was not possible to stratify complications according to the Clavien-Dindo scale [8]. Meta-analysis showed that statistical heterogeneity between studies was substantial $\left(I^{2}=48 \%\right.$, $p=0.02$ ). (Fig. 2.) The overall complication rate was significantly lower for initial NOT compared to EA (RR 0.37 
Fig. 1 PRISMA flow diagram of the study selection

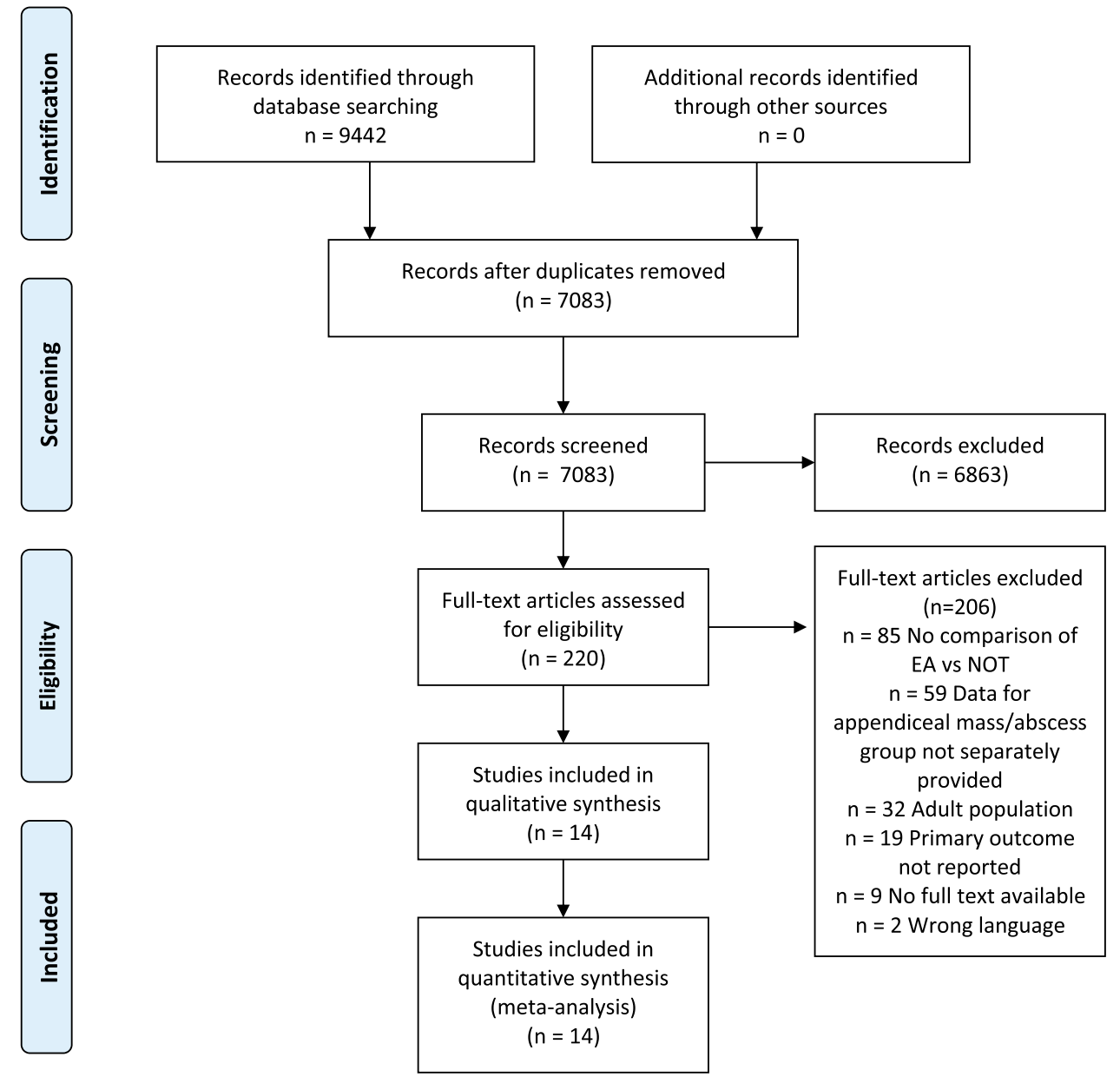

[95\% CI 0.21-0.64], $p=0.0004)[5,6,12-23]$. Both the sensitivity analysis including only studies published after 2000 and the sensitivity analysis including only studies that further specified their definition of appendiceal abscess and/ or mass (and thus not only mentioned the terms 'appendiceal mass/phlegmon' or 'appendiceal abscess'), showed similar results $[5,6,12,13,15-18,20,21]$. When only studies with moderate risk of bias were included in the analysis, the effect was no longer statistically significant (RR 0.31 [95\% CI 0.09-1.08], $p=0.07$ ) (Table 3) $[5,6,13,18,21]$.

\section{Subgroup analyses of the primary outcome}

Four studies reported specifically on appendiceal mass (total 731 patients, NOT $n=680$, EA $n=51$ ) $[12,19,20$, $22]$. In this subgroup 94 out of 680 patients (14\%) and ten out of 51 patients (20\%) experienced a complication after NOT and EA, respectively. Four other studies focused on appendiceal abscess (total 133 patients, NOT $\mathrm{n}=71$, EA $\mathrm{n}=62)[6,13,21,23]$. Eleven out of 71 patients $(15 \%)$ treated non-operatively and 32 out of 62 patients (52\%) that underwent EA for appendiceal abscess experienced a complication. Therefore in both subgroups NOT was associated with a lower risk of overall complications, although not significant. The other six studies did not specify between appendiceal abscess and mass and thus included children with mass, abscess, and both mass and abscess (total 491 patients, NOT $n=271$, EA $n=220$ ). Subgroup analysis of these studies showed a significantly lower overall complication rate in the NOT group [5, 14-18]. (Table 3, Fig. 3) Complications were further divided into IAA, wound infection, and ileus, which were the most reported complications. (Table 3, Fig. 3) Risk ratio of developing one of these complications was significantly lower for the initial NOT group compared to the EA group (RR 0.32 [95\%CI 0.16-0.63]; RR 0.13 [95\%CI 0.06-0.31]; RR 0.20 [95\%CI 0.07-0.54], respectively). (Table 3)

\section{Funnel plot}

The funnel plot regarding our primary outcome, overall complication rate, shows the possibility of some publication bias. Especially small cohort studies that favor EA are missing in current literature. (Online Appendix 3) 


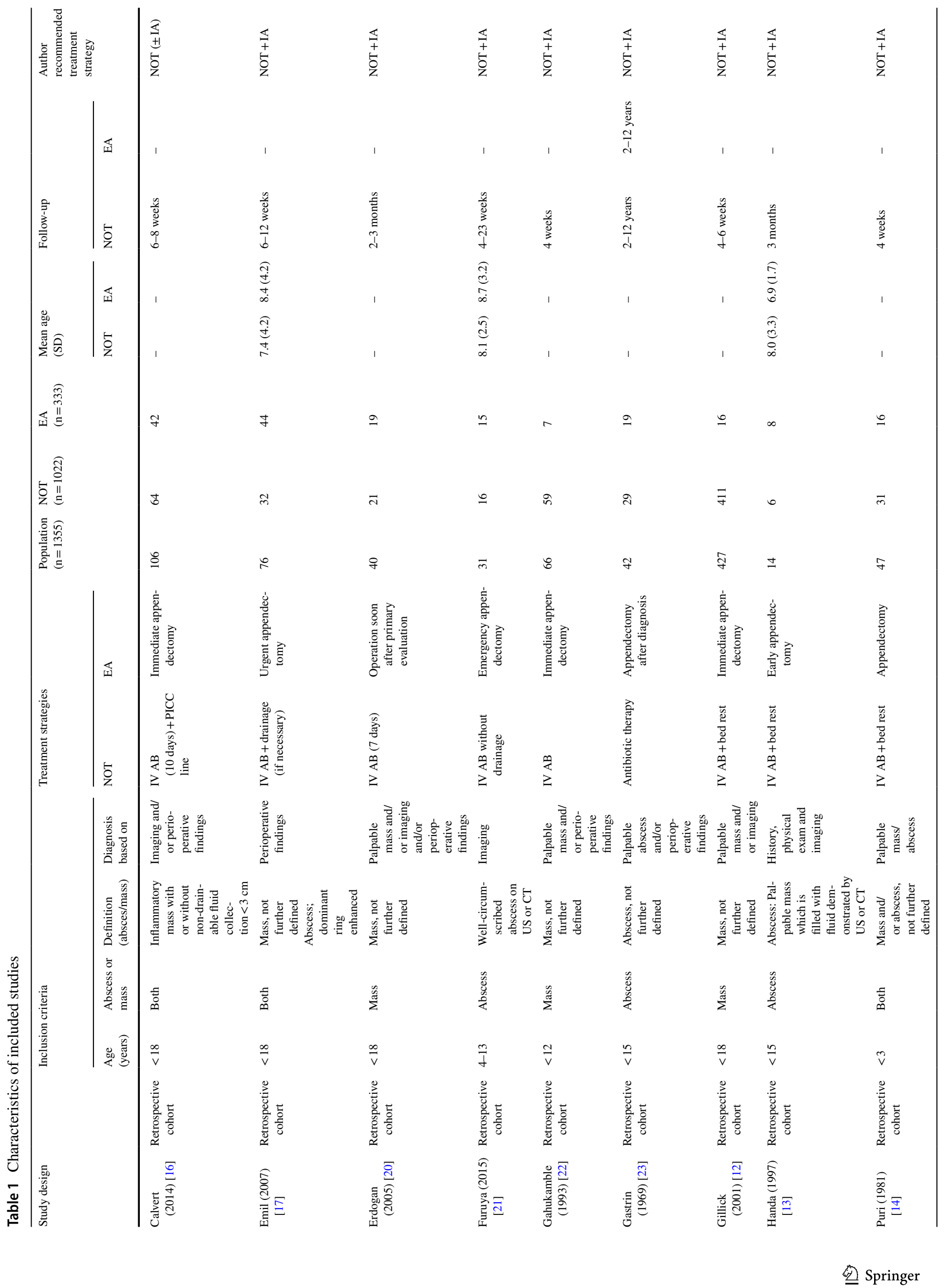


5240

Surgical Endoscopy (2020) 34:5234-5249

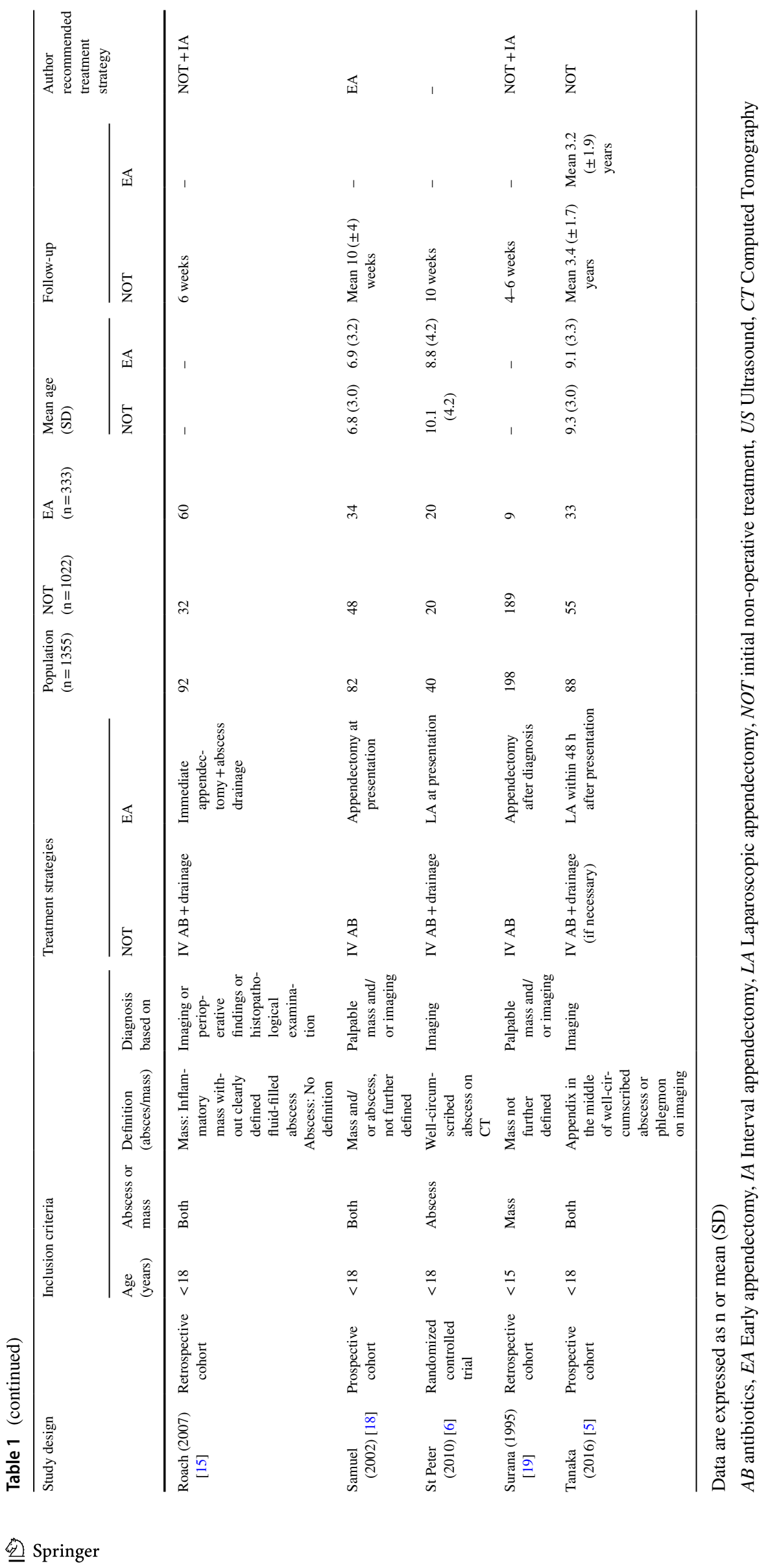




\section{Grade Evidence table}

The certainty of the evidence regarding the overall complication rate was considered to be very low according to the GRADE principles. (Table 4)

\section{Secondary outcomes}

\section{Length of hospital stay}

Only three studies accurately reported initial length of stay of a total of 210 patients $($ NOT $n=103$, EA $n=67)[5$, $18,20]$. The mean initial length of stay varied between 4.8 and 13.0 days in these populations. The difference in initial length of stay varied between 0.1 [20] and 5.9 days [18] in favor of the EA group. Only the study of Samuel reported a significantly longer initial length of stay for the non-operative group.

Total length of hospital stay was reported in nine papers and varied between 6.7 [6] and 28.6 days [21] for the NOT group and 4.8 [18] and 26.2 days [21] for the EA group $[5,6,12,13,15-18,21]$. Mean difference varied between 0.20 [6] and 8.40 days [18] in favor of the EA group. After pooling of the results, statistical heterogeneity was $99 \%$ and therefore it was decided not to show the pooled effect estimate. The considerable heterogeneity could be caused by the very small standard deviations that were reported in two studies, of which one study found a large mean difference in length of stay in favor of the EA group [15, 18].

However, if only studies with moderate risk of bias were included, statistical heterogeneity remained higher than $70 \%$ (i.e., $79 \%$ ) [5, 6, 13, 21].

\section{Readmission rate}

Readmission rate was described in eight studies and was not statistically different between intervention groups $(\mathrm{n}=1001$, RR 1.75 [95\%CI 0.79-3.89], $p=0.17 ; I^{2}=0$; Table 3) [5, $12,13,15,17,19,20,22]$. Both sensitivity analysis including only studies with moderate risk of bias, and sensitivity analysis including only studies published after 2000, did not alter this outcome (Table 3) [5, 12, 13, 15, 17, 20].

\section{Recurrence rate}

Interval appendectomy was part of the NOT strategy in all but one study [6, 12-23]. In this patient preference study, only 16 of 55 (29\%) patients who underwent NOT, desired interval appendectomy [5]. Recurrence rate prior to interval appendectomy ranged from $0 \%[15]$ to $12.5 \%[5,12-14,17$, 19-23]. Recurrence rate in patients treated with an initial
NOT strategy without interval appendectomy was 34\% within a mean \pm SD follow-up period of $3.4 \pm 1.7$ years [5]

\section{Imaging studies and usage of pain medication}

Number and type of imaging studies and number of doses of pain medication were compared in only one study [6]. A lower number of CT-scans was performed in children that underwent $\mathrm{EA}$ versus NOT (mean \pm SD $1.5 \pm 0.7$ versus $2.1 \pm 1.1 ; p=0.04)$. Number of doses of pain medication was not significantly different between groups (mean \pm SD $9.7 \pm 4.0$ (EA group) versus $7.1 \pm 15.8$ (NOT group)).

\section{Histopathological examination}

Eight papers described the results of histopathological examination [5, 12, 13, 17-20, 22]. Unexpected findings were found in two studies $[12,18]$. Both found carcinoid tumors in 2 out of 331 patients $(0.6 \%)$ and 1 out of 48 (2.1\%) patients, respectively.

\section{Number of interventions}

Interventions described in the included studies were EA, interval appendectomy, drainage procedures, placement of peripherally inserted central catheters (PICC-lines), and reoperations (e.g., due to adhesive small bowel obstruction) $[5,6,12-23]$. The number of interventions ranged between 1 and 2 per patient in both treatment groups.

\section{Quality of life}

None of the studies reported on Quality of Life.

\section{Discussion}

In daily practice, there is still no consensus regarding the optimal treatment strategy for children presenting with an appendiceal abscess or mass due to complex appendicitis. Studies regarding this topic are scarce, of low quality and the heterogeneity between studies is substantial. Therefore results of these studies and our review should be interpreted with caution. But, based on the available low-quality data, it seems that initial NOT may reduce the overall complication rate compared to EA in the overall group (thus appendiceal abscess and mass), without significantly increasing neither the total length of hospital stay nor the readmission rate, but the evidence is very uncertain. Nonetheless, the scarce and low-quality evidence emphasizes 
Table 2 Risk of Bias on the primary outcome (overall complication rate) in included studies

\begin{tabular}{|c|c|c|c|c|c|c|c|c|}
\hline \multirow{2}{*}{$\begin{array}{l}\text { Article } \\
\\
\text { St Peter (2010) } \\
{[6]^{*}}\end{array}$} & \multicolumn{2}{|c|}{$\begin{array}{l}\text { Risk of bias arising from the } \\
\text { randomization process }\end{array}$} & \multirow{2}{*}{$\begin{array}{l}\text { Risk of bias } \\
\text { due to devia- } \\
\text { tions from } \\
\text { the intended } \\
\text { interventions } \\
\text { Low }\end{array}$} & \multirow{2}{*}{$\begin{array}{l}\text { Missing out- } \\
\text { come data } \\
\\
\text { Low }\end{array}$} & \multirow{2}{*}{$\begin{array}{l}\text { Risk of bias } \\
\text { in measure- } \\
\text { ment of the } \\
\text { outcome } \\
\begin{array}{c}\text { Some con- } \\
\text { cerns }\end{array}\end{array}$} & \multirow{2}{*}{$\begin{array}{l}\text { Risk of bias } \\
\text { in selection of } \\
\text { the reported } \\
\text { result } \\
\text { Unclear }\end{array}$} & \multicolumn{2}{|c|}{ Overall risk of bias } \\
\hline & Low & & & & & & Some concern & \\
\hline Article & $\begin{array}{l}\text { Bias due to } \\
\text { confound- } \\
\text { ing }\end{array}$ & $\begin{array}{l}\text { Bias in selec- } \\
\text { tion of par- } \\
\text { ticipants into } \\
\text { the study }\end{array}$ & $\begin{array}{l}\text { Bias in clas- } \\
\text { sification of } \\
\text { interventions }\end{array}$ & $\begin{array}{l}\text { Bias due } \\
\text { to devia- } \\
\text { tions from } \\
\text { intended } \\
\text { interven- } \\
\text { tions }\end{array}$ & $\begin{array}{l}\text { Bias due to } \\
\text { missing data }\end{array}$ & $\begin{array}{c}\text { Bias in meas- } \\
\text { urement of } \\
\text { outcomes }\end{array}$ & $\begin{array}{l}\text { Bias in selec- } \\
\text { tion of the } \\
\text { reported } \\
\text { result }\end{array}$ & $\begin{array}{l}\text { Overall Risk } \\
\text { of Bias }\end{array}$ \\
\hline $\begin{array}{l}\text { Calvert (2014) } \\
{[16]}\end{array}$ & Serious & Moderate & Moderate & Low & Low & Moderate & NI & Serious \\
\hline Emil (2007) [17] & Serious & Serious & Serious & Low & Moderate & Moderate & NI & Serious \\
\hline $\begin{array}{l}\text { Erdogan (2004) } \\
\text { [20] }\end{array}$ & Serious & Moderate & Moderate & Low & Low & Moderate & NI & Serious \\
\hline $\begin{array}{l}\text { Furuya (2015) } \\
\text { [21] }\end{array}$ & Moderate & Low & Moderate & Low & Low & Moderate & Moderate & Moderate \\
\hline $\begin{array}{l}\text { Gahukamble } \\
\text { (1993) [22] }\end{array}$ & Serious & Low & Moderate & Low & Serious & Moderate & NI & Serious \\
\hline $\begin{array}{l}\text { Gästrin (1969) } \\
\text { [23] }\end{array}$ & Serious & Serious & Serious & Low & Moderate & Moderate & NI & Serious \\
\hline $\begin{array}{l}\text { Gillick (2001) } \\
\text { [12] }\end{array}$ & Serious & Low & Moderate & Low & Low & Moderate & NI & Serious \\
\hline $\begin{array}{l}\text { Handa (1997) } \\
\text { [13] }\end{array}$ & Moderate & Low & Moderate & Low & Low & Moderate & Moderate & Moderate \\
\hline Puri (1981) [14] & Serious & Low & Serious & Low & Low & Moderate & NI & Serious \\
\hline $\begin{array}{l}\text { Roach }(2007) \\
{[15]}\end{array}$ & Serious & Moderate & Moderate & Low & Low & Moderate & Moderate & Serious \\
\hline $\begin{array}{l}\text { Samuel (2002) } \\
\text { [18] }\end{array}$ & Moderate & Low & Low & Low & Low & Moderate & Moderate & Moderate \\
\hline $\begin{array}{l}\text { Surana (1995) } \\
\text { [19] }\end{array}$ & Serious & Low & Moderate & Low & Low & Moderate & NI & Serious \\
\hline $\begin{array}{l}\text { Tanaka (2016) } \\
\text { [5] }\end{array}$ & Moderate & Low & Low & Low & Low & Moderate & NI & Moderate \\
\hline
\end{tabular}

*The Cochrane Collaboration's Risk of Bias Tool for randomized controlled trials was applied for this study. Risk of bias for all other studies was assessed with the Risk of Bias in Non-randomized Studies of Interventions tool (ROBINS-1)

NI No Information

Fig. 2 Overall complication rate

\begin{tabular}{|c|c|c|c|c|c|c|c|c|c|c|}
\hline \multirow{2}{*}{$\begin{array}{l}\text { Study or Subgroup } \\
\text { Calvert } 2014\end{array}$} & $\begin{array}{r}\text { NOT } \\
\text { Events } \\
\end{array}$ & Total & \multirow{2}{*}{$\begin{array}{r}\text { EA } \\
\text { Events } \\
12\end{array}$} & \multirow{2}{*}{$\begin{array}{r}\text { Total } \\
42\end{array}$} & \multirow{2}{*}{$\begin{aligned} \text { Weight } \\
9.4 \%\end{aligned}$} & \multirow{2}{*}{$\begin{array}{c}\text { Risk Ratio } \\
\text { M-H, Random, } 95 \% \mathrm{Cl}\end{array}$} & \multicolumn{4}{|c|}{$\begin{array}{c}\text { Risk Ratio } \\
\text { M-H, Random, } 95 \% \text { Cl }\end{array}$} \\
\hline & 3 & 64 & & & & & & & & \\
\hline Emil 2007 & 2 & 32 & 3 & 44 & $6.4 \%$ & $0.92[0.16,5.17]$ & & & & \\
\hline Erdogan 2005 & 0 & 21 & 5 & 19 & $3.1 \%$ & $0.08[0.00,1.40]$ & & & - & \\
\hline Furuya 2015 & 0 & 16 & 13 & 15 & $3.3 \%$ & $0.03[0.00,0.54]$ & & & & \\
\hline Gahukamble 1993 & 2 & 59 & 2 & 7 & $6.1 \%$ & $0.12[0.02,0.72]$ & & & & \\
\hline Gastrin 1969 & 6 & 29 & 9 & 19 & $11.9 \%$ & $0.44[0.19,1.03]$ & & & & \\
\hline Gillick 2001 & 65 & 411 & 2 & 16 & $8.6 \%$ & $1.27[0.34,4.71]$ & & & & \\
\hline Handa 1997 & 0 & 6 & 5 & 8 & $3.3 \%$ & $0.12[0.01,1.78]$ & & & & \\
\hline Puri 1981 & 3 & 31 & 11 & 16 & $9.9 \%$ & $0.14[0.05,0.43]$ & & & & \\
\hline Roach 2007 & 0 & 32 & 5 & 60 & $3.1 \%$ & $0.17[0.01,2.95]$ & & & & \\
\hline Samuel 2002 & 9 & 57 & 4 & 25 & $10.2 \%$ & $0.99[0.34,2.91]$ & & & & \\
\hline St Peter 2010 & 5 & 20 & 5 & 20 & $10.2 \%$ & $1.00[0.34,2.93]$ & & & & \\
\hline Surana 1995 & 27 & 189 & 1 & 9 & $5.7 \%$ & $1.29[0.20,8.43]$ & & & & \\
\hline Tanaka 2016 & 3 & 55 & 7 & 33 & $8.8 \%$ & $0.26[0.07,0.93]$ & & & & \\
\hline Total $(95 \% \mathrm{Cl})$ & & 1022 & & 333 & $100.0 \%$ & $0.37[0.21,0.64]$ & & & & \\
\hline Total events & 125 & & 85 & & & & & & & \\
\hline $\begin{array}{l}\text { Heterogeneity: } \mathrm{Tau}^{2}= \\
\text { Test for overall effect }\end{array}$ & $\begin{array}{l}0.49 ; \mathrm{Chi}^{2} \\
=3.54(\mathrm{P}\end{array}$ & $\begin{array}{l}=25.05 \\
P=0.0\end{array}$ & $\begin{array}{l}5, \mathrm{df}=13 \\
004)\end{array}$ & $(P=0$. & $02) ; 1^{2}=4$ & & 0.01 & $\begin{array}{l}1 \\
\text { Favours NOT }\end{array}$ & \begin{tabular}{|rr}
10 \\
Favours EA
\end{tabular} & 100 \\
\hline
\end{tabular}


Table 3 Results of meta-analyses of early appendectomy vs non-operative treatment on primary and secondary outcomes

\begin{tabular}{|c|c|c|c|c|c|c|c|}
\hline Outcome & No. of studies & $\begin{array}{l}\text { Total } \\
\text { partici- } \\
\text { pants }\end{array}$ & $\begin{array}{l}\text { Par- } \\
\text { ticipants } \\
\text { NOT }\end{array}$ & Participants EA & $\begin{array}{l}\text { Hetero- } \\
\text { geneity } \\
I^{2}, \%\end{array}$ & Risk Ratio (95\% CI) & $p$ value \\
\hline \multicolumn{8}{|l|}{ Primary outcome } \\
\hline Overall complications $[5,6,12-23]$ & 14 & 1355 & 1022 & 333 & 48 & $0.37(0.21-0.64)$ & 0.0004 \\
\hline \multicolumn{8}{|l|}{ Subgroup mass/abscess } \\
\hline $\begin{array}{l}\text { Overall complications (only mass) }[12,19 \text {, } \\
20,22]\end{array}$ & 4 & 731 & 680 & 51 & 56 & $0.44(0.11-1.80)$ & 0.25 \\
\hline $\begin{array}{l}\text { Overall complications (only abscess) [6, } \\
13,21,23]\end{array}$ & 4 & 133 & 71 & 62 & 63 & $0.33(0.09-1.17)$ & 0.09 \\
\hline $\begin{array}{l}\text { Overall complications (combination of } \\
\text { mass and abscess) }[5,14-18]\end{array}$ & 6 & 491 & 271 & 220 & 47 & $0.31(0.14-0.69)$ & 0.004 \\
\hline \multicolumn{8}{|l|}{ Subgroup type of complication } \\
\hline IAA $[5,6,12,14-17,19-23]$ & 12 & 1253 & 953 & 300 & 16 & $0.32(0.16-0.63)$ & 0.001 \\
\hline Wound infection [12-14, 16-22] & 10 & 1081 & 880 & 201 & 0 & $0.13(0.06-0.31)$ & $<0.00001$ \\
\hline Ileus $[5,6,12-14,16,19,21,23]$ & 9 & 993 & 815 & 178 & 0 & $0.20(0.07-0.54)$ & 0.001 \\
\hline \multicolumn{8}{|l|}{ Sensitivity analyses } \\
\hline $\begin{array}{l}\text { Overall complications }(\mathrm{RoB})^{\mathrm{a}}[5,6,13 \text {, } \\
\quad 18,21]\end{array}$ & 5 & 255 & 154 & 101 & 62 & $0.39(0.13-1.17)$ & 0.09 \\
\hline $\begin{array}{l}\text { Overall complications (further specified } \\
\text { definition) })^{b}[5,6,13,15-17,21]\end{array}$ & 7 & 447 & 225 & 222 & 48 & $0.29(0.12-0.71)$ & 0.007 \\
\hline $\begin{array}{l}\text { Overall complications (studies published } \\
\text { after 2000) }[5,6,12,15-18,20,21]\end{array}$ & 9 & 982 & 708 & 274 & 55 & $0.42(0.19-0.90)$ & 0.03 \\
\hline \multicolumn{8}{|l|}{ Secondary outcomes } \\
\hline $\begin{array}{l}\text { Readmission rate }[5,12,13,15,17,19, \\
20,22]\end{array}$ & 8 & 1001 & 805 & 196 & 0 & $1.75(0.79-3.89)$ & 0.17 \\
\hline \multicolumn{8}{|l|}{ Sensitivity analyses } \\
\hline Readmission rate $(\mathrm{RoB})^{\mathrm{a}}[5,13]$ & 2 & 102 & 61 & 41 & 21 & $1.89(0.43-8.44)$ & 0.40 \\
\hline $\begin{array}{l}\text { Readmission rate (studies published after } \\
\text { 2000) }[5,12,15,17,20]\end{array}$ & 5 & 723 & 551 & 172 & 16 & $2.15(0.72-6.39)$ & 0.17 \\
\hline
\end{tabular}

${ }^{\text {a }}$ Sensitivity analysis including only studies with a moderate risk of bias

${ }^{\mathrm{b}}$ Sensitivity analysis including only studies that reported a clear definition of appendiceal mass and/or abscess

Data are expressed as $\mathrm{n}$ or mean, unless otherwise specified

$R O B$ risk of bias, $I A A$ intra-abdominal abscess

the importance of well-designed high quality studies and, for in the meantime, shared decision making.

To our knowledge, this review was the first to focus solely on the treatment of the specific subgroup of pediatric patients with appendiceal mass and abscess. Three slightly comparable meta-analyses have been published on this topic. However, one of those focused on both the adult and pediatric population and performed a subgroup analysis for children with appendiceal mass and/or abscess [3]. The other two more recent meta-analyses focused on the treatment of complex appendicitis in the pediatric population but focused on complex appendicitis in general and therefore included both patients with mass and/or abscess but also those without (only free perforation)) [24, 25].

All three meta-analysis have comparable results, which are in line with our review. The first mentioned meta-analysis was published in 2010 and included seven studies, of which four that were also included in our meta-analysis. They found a lower overall complication rate for initial NOT as well (OR 0.21 [95\%CI 0.11-0.38]) [3]. The two more recent studies performed a subgroup/sensitivity analysis for studies reporting on children with a mixture of appendiceal mass and/or abscess, including eight (of which two were included in our meta-analysis) and four studies (all included in our meta-analysis), respectively, and found a lower overall complication rate for initial NOT as well (OR 0.27 [95\%CI 0.08-0.85] [24] and RR 0.06 [95\%CI 0.02-0.23] [25]). Our review support these findings and contributes due to the fact that our meta-analysis displays a more accurate estimation of the overall effect size compared to the others. Our predefined inclusion criteria selected a less heterogeneous group of solely children with appendiceal mass and/or abscess and we included a total number of 14 studies, whereas previous meta-analyses only included four [25], seven [3], and eight 


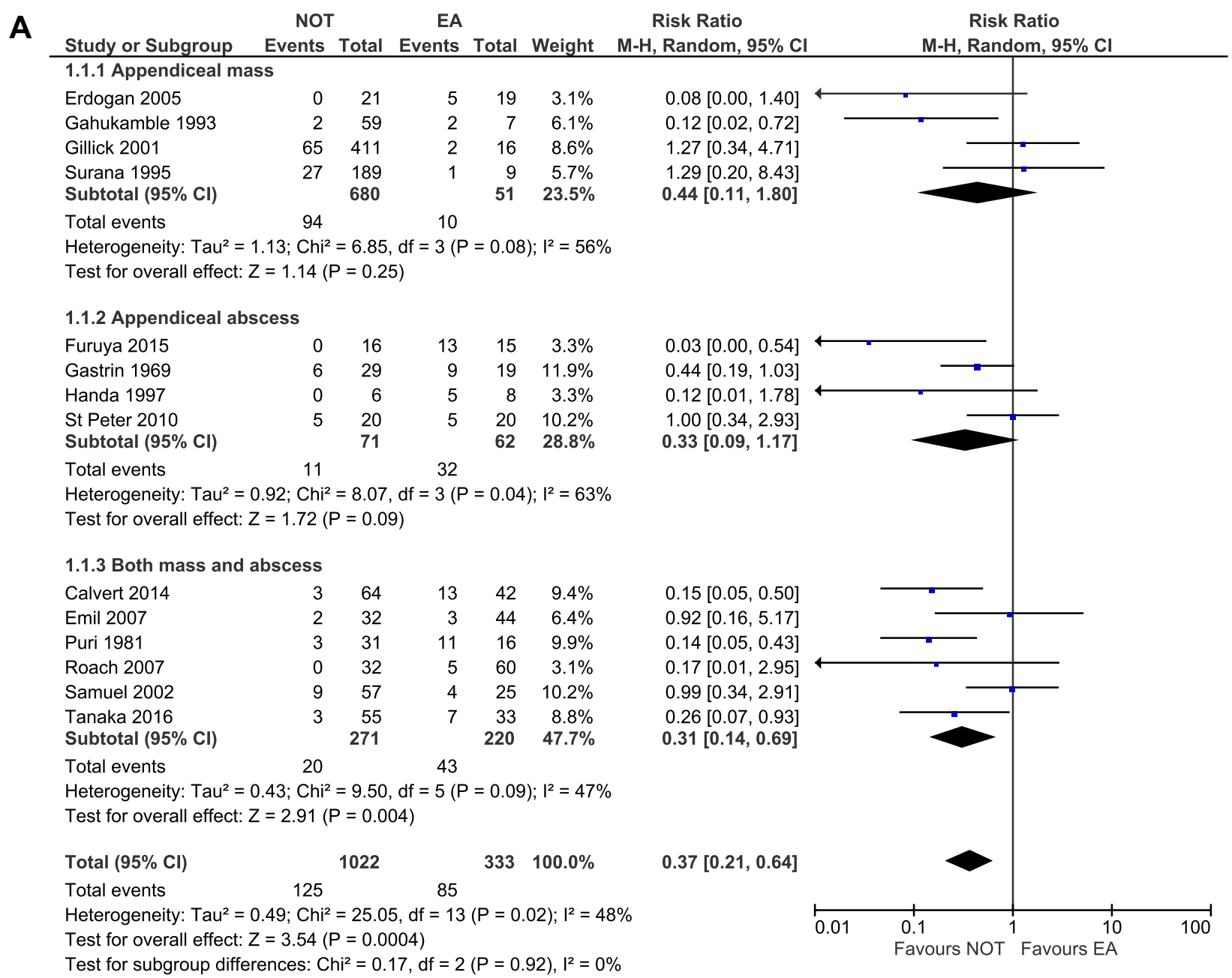

Fig. 3 a Forest plot of subgroup analyses on overall complications. b Forest plot on subgroup analyses on type of complication. Upper forest plot: IAA, middle forest plot: Wound infection, lower forest plot: Ileus

studies [24] in a subgroup analysis of a mixture of children with appendiceal mass, abscess, and both.

Furthermore our review has also integrated a subgroup analysis for the patients with an appendiceal mass and abscess individually, which has not been done in previous studies. Interestingly, in our subgroup analyses the only group with a significantly different overall complication rate between initial NOT and EA was the group with a mixture of appendiceal mass, abscess and both. Although this may have been caused by a type two error, in our review no significant difference was found in the subgroups of children with only an appendiceal mass or appendiceal abscess.

Focusing on the secondary outcomes, we are the first to describe the number of interventions, imaging studies, and doses of pain medication. Other secondary outcomes such as readmission rate were previously described and found to be higher in the EA group, which could not be confirmed by our review. Additionally, our review found a longer total length of hospital stay after NOT, although results could not be pooled due to significant heterogeneity. This longer length of stay after NOT could be explained by the second admission that was scheduled for interval appendectomy in almost all included studies, as initial length of stay did not differ between treatment groups. This systematic review and meta-analysis could only include one study that did not routinely perform an interval appendectomy. This study found a recurrence rate of $34 \%$ in a group of 38 patients during a mean follow-up period of $3.4 \pm 1.7$ years [5]. However, recent studies, including a large randomized controlled trial, have shown that a wait-and-see approach is justified after non-operative treatment for appendiceal mass, as recurrence rates are low and unexpected findings (such as malignancies) are rarely found after interval appendectomy in the pediatric population [26-30]. This wait-and-see approach after NOT 
B

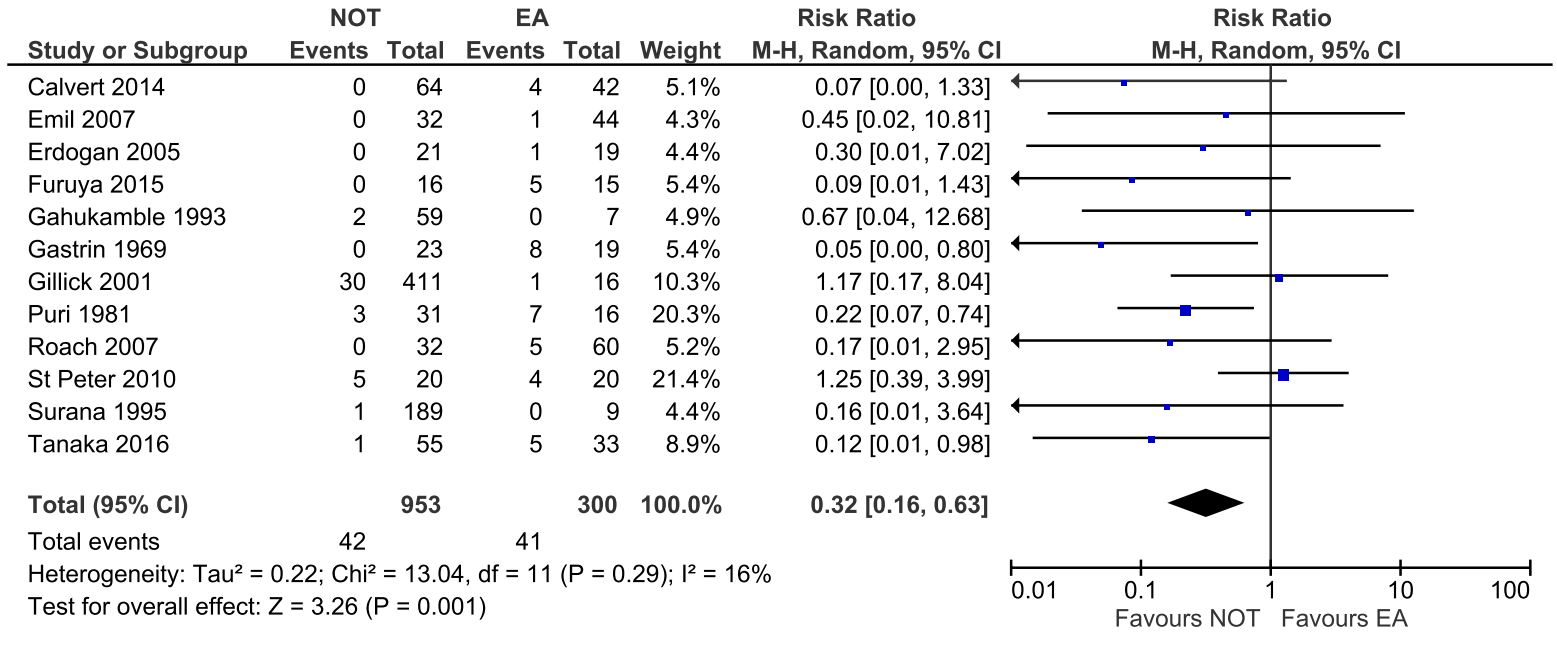

NOT EA Risk Ratio

Study or Subgroup Events Total Events Total Weight M-H, Random, 95\% Cl

\begin{tabular}{|c|c|c|c|c|c|}
\hline Calvert 2014 & 1 & 58 & 0 & 42 & $7.0 \%$ \\
\hline Emil 2007 & 0 & 32 & 2 & 44 & $7.8 \%$ \\
\hline Erdogan 2005 & 0 & 21 & 1 & 19 & $7.1 \%$ \\
\hline Furuya 2015 & 0 & 16 & 6 & 15 & $9.0 \%$ \\
\hline Gahukamble 1993 & 1 & 59 & 2 & 7 & $13.7 \%$ \\
\hline Gillick 2001 & 5 & 411 & 1 & 16 & $16.1 \%$ \\
\hline Handa 1997 & 0 & 6 & 2 & 8 & $8.5 \%$ \\
\hline Puri 1981 & 0 & 31 & 9 & 16 & $9.1 \%$ \\
\hline Samuel 2002 & 0 & 57 & 4 & 25 & $8.5 \%$ \\
\hline Surana 1995 & 2 & 189 & 1 & 9 & $13.2 \%$ \\
\hline Total $(95 \% \mathrm{Cl})$ & & 880 & & 201 & $100.0 \%$ \\
\hline Total events & 9 & & 28 & & \\
\hline $\begin{array}{l}\text { Heterogeneity: Tau } \\
\text { Test for overall effe }\end{array}$ & $\begin{array}{ll}C^{2} \\
3\end{array}$ & & 9 & & \\
\hline
\end{tabular}

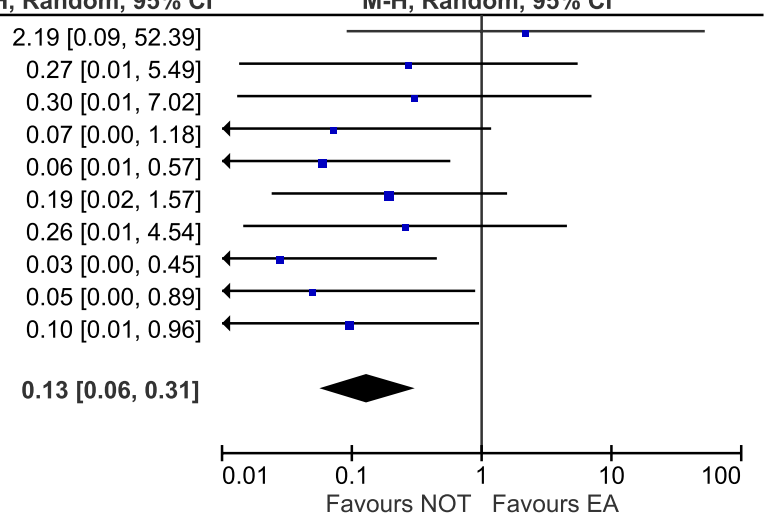

NOT

EA

Risk Ratio

Study or Subgroup Events Total Events Total Weight M-H, Random, 95\% Cl

\begin{tabular}{|c|c|c|c|c|c|}
\hline Calvert 2014 & 0 & 64 & 5 & 42 & $12.0 \%$ \\
\hline Furuya 2015 & 0 & 16 & 2 & 15 & $11.3 \%$ \\
\hline Gastrin 1969 & 0 & 23 & 1 & 19 & $10.0 \%$ \\
\hline Gillick 2001 & 3 & 411 & 0 & 16 & $11.6 \%$ \\
\hline Handa 1997 & 0 & 6 & 2 & 8 & $12.0 \%$ \\
\hline Puri 1981 & 0 & 31 & 3 & 16 & $11.7 \%$ \\
\hline St Peter 2010 & 1 & 20 & 0 & 20 & $10.0 \%$ \\
\hline Surana 1995 & 1 & 189 & 0 & 9 & $10.0 \%$ \\
\hline Tanaka 2016 & 0 & 55 & 3 & 33 & $11.5 \%$ \\
\hline Total $(95 \% \mathrm{Cl})$ & & 815 & & 178 & $100.0 \%$ \\
\hline Total events & 5 & & 16 & & \\
\hline
\end{tabular}

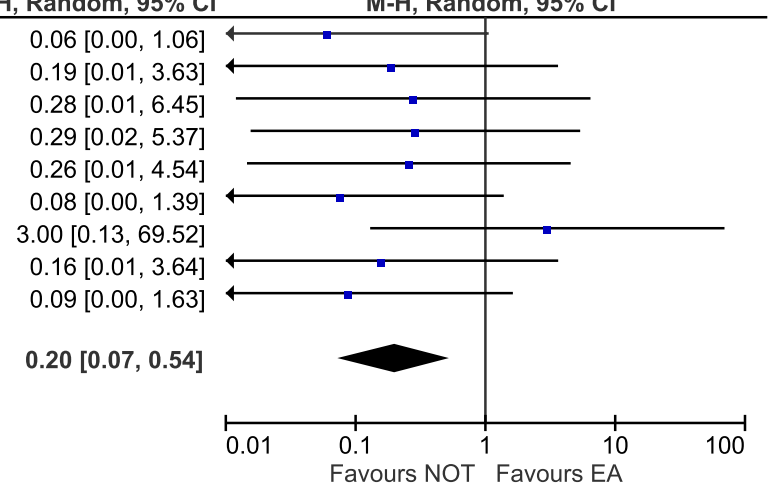

Fig. 3 (continued) 


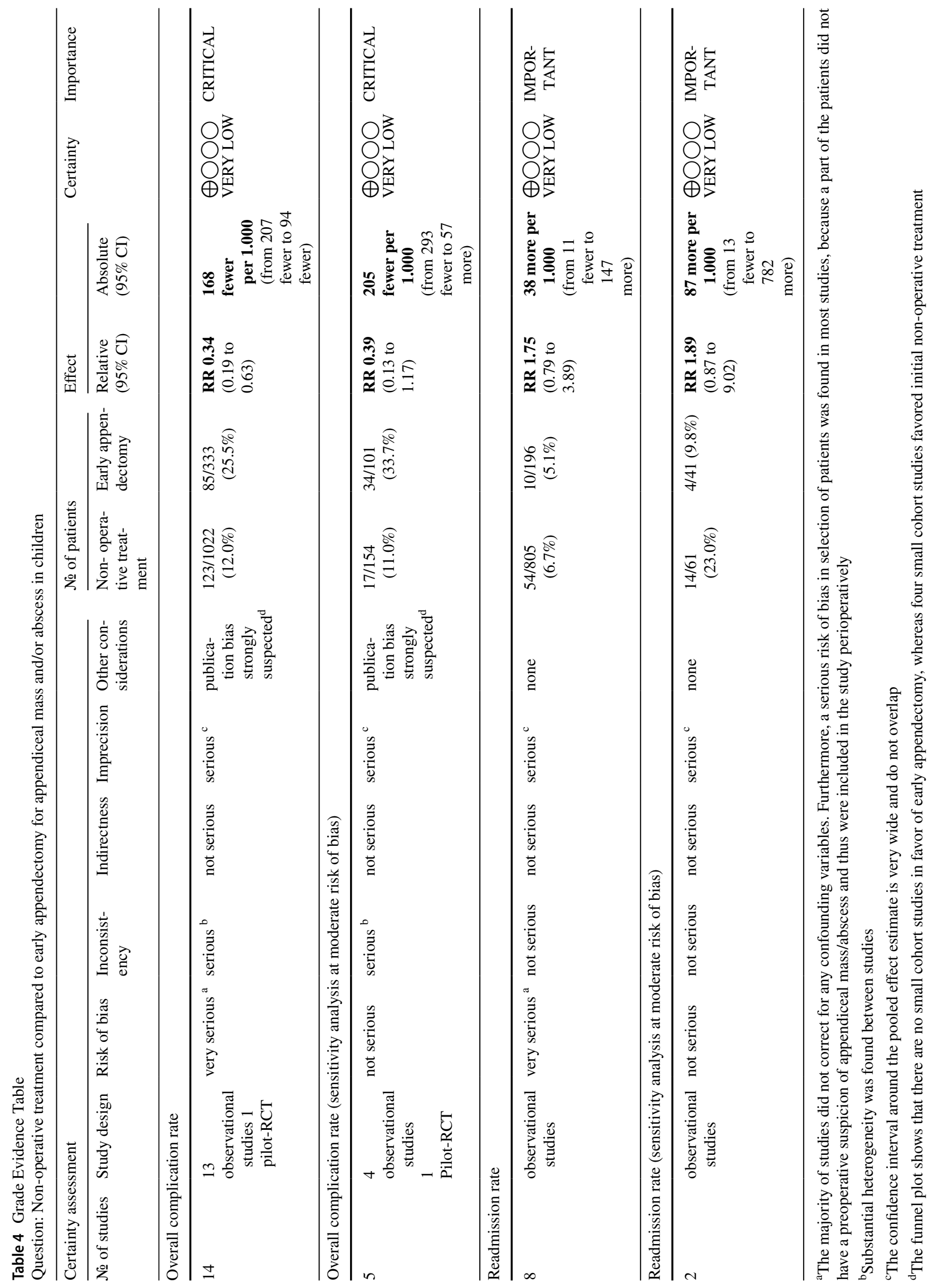


would possibly reduce the potential benefit of a shorter total length of hospital stay after EA.

Contrary to the pediatric population, initial NOT is the standard of care for adult patients presenting with appendiceal mass and or abscess. Systematic reviews and metaanalyses have shown that EA results in a significantly higher overall complication rate, and more specifically a greater incidence of ileus/bowel obstruction, IAA, and wound infection $[3,31]$. In the pediatric population, opponents of the initial NOT strategy hypothesize that the omentum is relatively smaller and underdeveloped in young children. Therefore a contained appendiceal mass is rarely seen perioperatively, which should lead to a significantly lower postoperative complication rate in these children [32,33]. Thus it can be hypothesized that EA might be preferable in young children, and on the other hand older children and adolescents might benefit from NOT. Although available evidence is limited, this hypothesis could not be validated by our review as a higher overall complication rate after EA was found for young children as well [14, 22].

Furthermore, it can be expected that differences in operation techniques (i.e., open versus laparoscopic appendectomy) can be of influence on the complication rate. Previous studies found a significantly lower complication rate after laparoscopic appendectomy (15.30\%) compared to open appendectomy (29.33\%) for complex appendicitis [34]. However, due to the limited data available, the EA group could not be divided into laparoscopic and open appendectomy in our systematic review and meta-analysis.

The most important and major concern of not only this review but all studies reporting on the treatment of appendiceal mass and abscess is the lack of consensus regarding the definition of both appendiceal mass and abscess. In addition the terms 'mass' and 'phlegmon' are frequently used as substitutes in the current literature. The lack of an uniform definition leads to considerable heterogeneity between studies $[35,36]$. Therefore interpretation of results and especially comparison of different study populations is difficult. In our review we attempted to solve this problem by using predefined criteria for appendiceal mass and abscess in our selection process. However, most studies did not provide a detailed definition and only reported the terms appendiceal 'mass', 'phlegmon', and 'abscess'. As a result we had to restrict our predefined criteria and included only studies that at least mentioned those terms to describe their study population. In our opinion, it is of utmost importance that consensus is reached regarding uniform definitions for appendiceal mass and abscess (e.g., through a Delphi study which we are currently planning) and that future studies make use of them. These uniform definitions can help to include comparable study populations in future studies, which are needed to draw proper conclusions regarding the optimal treatment strategy for children with appendiceal mass and abscess.
Apart from the mentioned lack of consensus regarding the definition of appendiceal mass, the results of this review are hampered by the heterogeneity between the included studies. Differences in methodology, in- and exclusion criteria, age, duration and type of antibiotics could all influence the outcome of the study. Several studies included both children with appendiceal mass and abscess, whereas others specified to one of both conditions. It was decided to pool data of both subgroups, because of the limited number of studies that reported specifically on one of the subgroups. Because of this limitation, subgroup analyses were performed for studies reporting on appendiceal mass, appendiceal abscess, and a combination of both.

In addition, differences in the diagnosis of appendiceal mass and abscess were found between studies. Whereas some studies only included patients that had ultrasound or CT-proven appendiceal mass and abscess, others included patients with a palpable mass or a mass that was found perioperatively. Moreover the majority of studies did not report the clinical status of patients at presentation, the size of the mass and abscess, and demographics and did not control for these confounders in their analysis. Due to their retrospective design and the aforementioned concerns, most studies were prone to significant selection bias.

Furthermore the majority of included studies were small retrospective cohort studies. Only two prospective cohort studies, and one pilot randomized controlled trial could be included in this review. All studies were assessed as having moderate to serious risk of bias. This illustrates the necessity of high quality prospective studies regarding this topic.

In conclusion, high quality evidence regarding the optimal treatment strategy for children presenting with appendiceal mass or abscess is missing and substantial heterogeneity exists between studies. Initial NOT of children with an appendiceal mass or abscess may reduce the overall complication rate compared to EA, but the evidence is very uncertain. The results of this review illustrate the necessity of a uniform definition of appendiceal mass and abscess, and subsequent large prospective studies are needed to determine the optimal treatment strategy for children presenting with an appendiceal mass or abscess.

Funding: Drs Paul van Amstel, Drs Tania C Sluckin, Tim van Amstel, Dr. Johanna H. van der Lee, Drs Ralph de Vries, Dr. Joep PM Derikx, Dr. Roel Bakx, Prof. Dr. LW Ernest van Heurn, and Dr. Ramon R. Gorter have no conflicts of interest or financial ties to disclose for the submitted work. Outside the submitted work Dr. Ramon R. Gorter and Dr. R. Bakx received a (governmental) ZonMw grant for research in the field of complex appendicitis in the pediatric population. Grant Number: 80-85009-98-2007. 


\section{Compliance with ethical standards}

Disclosures: Drs Paul van Amstel, Drs Tania C Sluckin, Tim van Amstel, Dr. Johanna H. van der Lee, Drs Ralph de Vries, Dr. Joep PM Derikx, Dr. Roel Bakx, Prof. Dr. LW Ernest van Heurn, and Dr. Ramon R. Gorter have no conflicts of interest or financial ties to disclose for the submitted work. Outside the submitted work, Dr. Ramon R. Gorter and Dr. Roel Bakx did receive a (governmental) ZonMw grant (Leading the Change program) for research in the field of complex appendicitis in the pediatric population. Grant number: 80-85009-98-2007.

Open Access This article is licensed under a Creative Commons Attribution 4.0 International License, which permits use, sharing, adaptation, distribution and reproduction in any medium or format, as long as you give appropriate credit to the original author(s) and the source, provide a link to the Creative Commons licence, and indicate if changes were made. The images or other third party material in this article are included in the article's Creative Commons licence, unless indicated otherwise in a credit line to the material. If material is not included in the article's Creative Commons licence and your intended use is not permitted by statutory regulation or exceeds the permitted use, you will need to obtain permission directly from the copyright holder. To view a copy of this licence, visit http://creativecommons.org/licenses/by/4.0/.

\section{References}

1. Bolmers MD, van Rossem CC, Gorter RR, Bemelman WA, van Geloven AAW, Heij HA (2018) Imaging in pediatric appendicitis is key to a low normal appendix percentage: a national audit on the outcome of appendectomy for appendicitis in children. Pediatr Surg Int. https://doi.org/10.1007/s00383-018-4244-2

2. van Rossem CC, Bolmers MDM, Schreinemacher MHF, van Geloven AAW, Bemelman WA (2016) Prospective nationwide outcome audit of surgery for suspected acute appendicitis. Br J Surg. https://doi.org/10.1002/bjs.9964

3. Simillis C, Symeonides P, Shorthouse AJ, Tekkis PP (2010) A meta-analysis comparing conservative treatment versus acute appendectomy for complicated appendicitis (abscess or phlegmon). Surgery. https://doi.org/10.1016/j.surg.2009.11.013

4. van Rossem CC, van den Boom AL, Bom WJ, Bos ME, van Geloven AAW, Gorter RR, Jacod BC, Knaapen M, Lammers R, van Meurs AHJ, Nederend J, Puylaert JBCM. Startpagina - Acute appendicitis - Richtlijn - Richtlijnendatabase. [Guideline database website Richtlijnendatabase.nl]. July 1, 2019. Available at: https ://richtlijnendatabase.nl/richtlijn/acute_appendicitis/startpagin a_-_acute_appendicitis.html. Accessed 6 Nov 2019

5. Tanaka Y, Uchida H, Kawashima H, Fujiogi M, Suzuki K, Takazawa S, Deie K, Amano H, Iwanaka T (2016) More than one-third of successfully nonoperatively treated patients with complicated appendicitis experienced recurrent appendicitis: Is interval appendectomy necessary? J Pediatr Surg. https://doi.org/10.1016/j.jpeds urg.2016.09.017

6. St. Peter SD, Aguayo P, Fraser JD, Keckler SJ, Sharp SW, Leys CM, Murphy JP, Snyder CL, Sharp RJ, Andrews WS, Holcomb GW 3rd, Ostlie DJ (2010) Initial laparoscopic appendectomy versus initial nonoperative management and interval appendectomy for perforated appendicitis with abscess: a prospective, randomized trial. J Pediatr Surg. https://doi.org/10.1016/j.jpeds urg.2009.10.039
7. Moher D, Liberati A, Tetzlaff J, Altman DG (2009) Preferred reporting items for systematic reviews and meta-analyses: the PRISMA statement. BMJ. https://doi.org/10.1136/bmj.b2535

8. Dindo D, Demartines N, Clavien PA (2004) Classification of surgical complications: a new proposal with evaluation in a cohort of 6336 patients and results of a survey. Ann Surg. https ://doi.org/10.1097/01.sla.0000133083.54934.ae

9. Sterne JAC, Savović J, Page MJ, Elbers RG, Blencowe NS, Boutron I, Cates CJ, Cheng HY, Corbett MS, Eldridge SM, Emberson JR, Hernán MA, Hopewell S, Hróbjartsson A, Junqueira DR, Jüni P, Kirkham JJ, Lasserson T, Li T, McAleenan A, Reeves BC, Shepperd S, Shrier I, Stewart LA, Tilling K, White IR, Whiting PF, Higgins JPT (2019) A revised tool for assessing risk of bias in randomized trials. BMJ. https://doi. org/10.1136/bmj.I4898

10. Sterne JA, Hernán MA, Reeves BC, Savović J, Berkman ND, Viswanathan M, Henry D, Altman DG, Ansari MT, Boutron I, Carpenter JR, Chan AW, Churchill R, Deeks JJ, Hróbjartsson A, Kirkham J, Jüni P, Loke YK, Pigott TD, Ramsay CR, Regidor D, Rothstein HR, Sandhu L, Santaguida PL, Schünemann HJ, Shea B, Shrier I, Tugwell P, Turner L, Valentine JC, Waddington H, Waters E, Wells GA, Whiting PF, Higgins JP (2016) ROBINS-I: a tool for assessing risk of bias in non-randomised studies of interventions. BMJ. https://doi.org/10.1136/bmj. i4919

11. Howick J, Chalmers I, Glasziou P, Greenhalgh T, Heneghan C, Liberati A, Moschetti I, Phillips B, Thornton H, Goddard O, Hodgkinson M. The Oxford 2011 Levels of Evidence. Oxford Centre Evidence-Based Medicine; 2011.

12. Gillick J, Velayudham M, Puri P (2001) Conservative management of appendix mass in children. Br J Surg. https://doi.org/1 0.1046/j.0007-1323.2001.01912.x

13. Handa N, Muramori K, Taguchi S (1997) Early appendectomy versus an interval appendectomy for appendiceal abscess in children. Fukuoka Igaku Zasshi. 88(12):389

14. Puri P, Boyd E, Guiney EJ, O’Donnell B (1981) Appendix mass in the very young child. J Pediatr Surg. https://doi.org/10.1016/ S0022-3468(81)80115-7

15. Roach JP, Partrick DA, Bruny JL, Allshouse MJ, Karrer FM, Ziegler MM (2007) Complicated appendicitis in children: a clear role for drainage and delayed appendectomy. Am J Surg. https://doi.org/10.1016/j.amjsurg.2007.08.021

16. Calvert CE, Tracy S, Zhou J, Graham D, Lebowitz M, Dennett KV, Chen C (2014) Treatment of perforated appendicitis in children: focus on phlegmon. Am Surg. 80(3):314

17. Emil S, Duong S (2007) Antibiotic therapy and interval appendectomy for perforated appendicitis in children: a selective approach. Am Surg. 73(8):917-922

18. Samuel M, Hosie G, Holmes K (2002) Prospective evaluation of nonsurgical versus surgical management of appendiceal mass. J Pediatr Surg. https://doi.org/10.1053/jpsu.2002.32895

19. Surana R, Puri P (1995) Appendiceal mass in children. Pediatr Surg Int. https://doi.org/10.1007/BF00171159

20. Erdoğan D, Karaman I, Narci A, Karaman A, Cavusoglu YH, Aslan MK, Cakmak O (2005) Comparison of two methods for the management of appendicular mass in children. Pediatr Surg Int. https://doi.org/10.1007/s00383-004-1334-0

21. Furuya T, Inoue M, Sugito K, Goto S, Kawashima H, Kaneda H, Masuko T, Ohashi K, Ikeda T, Koshinaga T (2015) Effectiveness of interval appendectomy after conservative treatment of pediatric ruptured appendicitis with abscess. Indian J Surg. https://doi.org/10.1007/s12262-014-1121-7

22. Gahukamble DB, Khamage AS, Gahukamble LD (1993) Management of appendicular mass in children. Ann Trop Paediatr. https://doi.org/10.1080/02724936.1993.11747672 
23. Gästrin U, Josephson S (1969) Appendiceal abscess-acute appendectomy or conservative treatment. Acta Chir Scand 135(6):539-542

24. Vaos G, Dimopoulou A, Gkioka E, Zavras N (2019) Immediate surgery or conservative treatment for complicated acute appendicitis in children? A meta-analysis. J Pediatr Surg. https://doi. org/10.1016/j.jpedsurg.2018.07.017

25. Fugazzola P, Coccolini F, Tomasoni M, Stella M, Ansaloni L (2019) Early appendectomy vs. conservative management in complicated acute appendicitis in children: a meta-analysis. J Pediatr Surg. https://doi.org/10.1016/j.jpedsurg.2019.01.065

26. Hall NJ, Eaton S, Stanton MP, Pierro A, Burge DM (2017) Active observation versus interval appendicectomy after successful nonoperative treatment of an appendix mass in children (CHINA study): an open-label, randomised controlled trial. Lancet Gastroenterol Hepatol. https://doi.org/10.1016/S2468-1253(16)30243 $-6$

27. Gorter RR, van Amstel P, van der Lee JH, van der Voorn P, Bakx R, Heij HA (2017) Unexpected findings after surgery for suspected appendicitis rarely change treatment in pediatric patients; results from a cohort study. J Pediatr Surg. https://doi. org/10.1016/j.jpedsurg.2017.02.012

28. Kim SS, Kays DW, Larson SD, Islam S (2014) Appendiceal carcinoids in children-management and outcomes. J Surg Res. https ://doi.org/10.1016/j.jss.2014.06.031

29. Fouad D, Kauffman JD, Chandler NM (2019) Pathology findings following interval appendectomy: should it stay or go? J Pediatr Surg. https://doi.org/10.1016/j.jpedsurg.2019.05.001

30. Otake S, Suzuki N, Takahashi A, Toki F, Nishi A, Yamamoto H, Kuroiwa M, Kuwano H (2014) Histological analysis of appendices removed during interval appendectomy after conservative management of pediatric patients with acute appendicitis with an inflammatory mass or abscess. Surg Today. https://doi. org/10.1007/s00595-014-0950-0

31. Andersson RE, Petzold MG (2007) Nonsurgical treatment of appendiceal abscess or phlegmon: a systematic review and metaanalysis. Ann Surg. https://doi.org/10.1097/SLA.0b013e3181 1f3f9f

32. Marzuillo P (2015) Appendicitis in children less than five years old: A Challenge for the general practitioner. World J Clin Pediatr. https://doi.org/10.5409/wjcp.v4.i2.19

33. Rasmussen OO, Hoffmann J (1991) Assessment of the reliability of the symptoms and signs of acute appendicitis. J R Coll Surg Edinb 6:372

34. Markar SR, Blackburn S, Cobb R, Karthikesalingam A, Evans J, Kinross J, Faiz O (2012) Laparoscopic versus open appendectomy for complicated and uncomplicated appendicitis in children. J Gastrointest Surg. https://doi.org/10.1007/s11605-012-1962-y

35. Cameron DB, Anandalwar SP, Graham DA, Melvin P, Serres SK, Dunlap JL, Kashtan M, Hall M, Saito JM, Barnhart DC, Kenney BD, Rangel SJ (2018) Development and implications of an evidence-based and public health-relevant definition of complicated appendicitis in children. Ann Surg. https://doi.org/10.1097/ sla.0000000000003059

36. Rogers AP, Zens TJ, Leys CM, Nichol PF, Ostlie DJ (2017) A call for a standardized definition of perforated appendicitis. J Pediatr Surg. https://doi.org/10.1016/j.jpedsurg.2016.10.026

Publisher's Note Springer Nature remains neutral with regard to jurisdictional claims in published maps and institutional affiliations.

\section{Affiliations}

\section{Paul van Amstel ${ }^{1}$ (D) Tania C. Sluckin ${ }^{1}$. Tim van Amstel ${ }^{1}$. Johanna H. van der Lee ${ }^{2,3} \cdot$ Ralph de Vries $^{4}$. Joep P. M. Derikx ${ }^{1} \cdot$ Roel Bakx $^{1} \cdot$ L. W. Ernest van Heurn ${ }^{1} \cdot$ Ramon R. Gorter $^{1}$}

Johanna H. van der Lee

j.h.vanderlee@amsterdamumc.nl

Ralph de Vries

R2.de.vries@vu.nl

Roel Bakx

r.bakx@amsterdamumc.nl

L. W. Ernest van Heurn

e.vanheurn@amsterdamumc.nl

Ramon R. Gorter

rr.gorter@amsterdamumc.nl
1 Emma Children's Hospital, Amsterdam UMC, University of Amsterdam \& Vrije Universiteit Amsterdam, Department of Pediatric Surgery, Amsterdam, The Netherlands

2 Emma Children's Hospital, Amsterdam UMC, University of Amsterdam, Pediatric Clinical Research Office Amsterdam, Amsterdam, The Netherlands

3 Knowledge Institute of the Dutch Association of Medical Specialists, Utrecht, The Netherlands

4 Vrije Universiteit Amsterdam, University Library, Amsterdam, The Netherlands 